\title{
An investigation of FSW process parameters effects on mechanical properties of PP composites
}

\author{
Fatemeh Kordestani, Faramarz Ashenai Ghasemi ${ }^{\mathrm{a}}$ and N.B. Mostafa Arab \\ Faculty of Mechanical Eng., Shahid Rajaee Teacher Training University, Tehran
}

Received 18 January 2016, Accepted 12 February 2016

\begin{abstract}
In this paper, effect of friction stir welding (FSW) process parameters on tensile and impact strength of polypropylene (PP) composite welds with 30\% short glass fiber and 30\% short carbon fiber are studied. Plates of $5 \mathrm{~mm}$ thickness were butt welded under different tool rotational speeds $(1250,1600$, 2000 and $2500 \mathrm{rpm}$ ), work linear speeds $\left(8,12,16\right.$ and $\left.20 \mathrm{~mm} \cdot \mathrm{min}^{-1}\right)$ and tool tilt angles $\left(3^{\circ}, 4^{\circ}, 5^{\circ}\right.$ and $6^{\circ}$ ) using the Taguchi method design of experiments (DOE). Standard tensile and Izod impact tests were carried out to determine tensile and impact strength of the welded joints. It was observed that for glass fiber composites the specimen welded at the rotational speed of $2000 \mathrm{rpm}$, linear speed of $8 \mathrm{~mm} . \mathrm{min}^{-1}$ and tilt angle of $6^{\circ}$ had the maximum tensile strength. For carbon fiber composites the specimen welded at the rotational speed of $2500 \mathrm{rpm}$, linear speed of $8 \mathrm{~mm} \cdot \mathrm{min}^{-1}$ and tilt angle of $6^{\circ}$ showed the maximum tensile strength. The maximum impact strength was also obtained at the rotational speed of $2500 \mathrm{rpm}$ and linear speed of $8 \mathrm{~mm} \cdot \mathrm{min}^{-1}$ for both composites whereas tilt angles of $5^{\circ}$ and $6^{\circ}$, caused maximum impact strength for glass and carbon fiber composites, respectively.
\end{abstract}

Key words: Carbon fiber (CF) / friction stir welding (FSW) / glass fiber (GF) / mechanical properties polypropylene (PP) / Taguchi method

\section{Introduction}

Friction stir welding (FSW) is a relatively new joining technique developed by the welding institute (TWI) Cambridge, in 1991 [1]. In FSW, a rotary tool is used and two pieces are held firmly together. The tool penetrates into work pieces with a rotational and linear motion to cause heating the work piece material due to friction between the tool and the work piece till the melt is formed. The linear and rotational movements of the tool in a molten pool create fusion of the work piece edges. After leaving the tool, the molten liquid freezes and two pieces are welded together $[2,3]$. The process occurs in the solid state and offers a number of advantages over conventional fusion welding techniques. Low heat input, absence of melting and solidification, no expensive consumables such as filler wire and gas shields, ease of automation, fewer weld defects, low residual stresses, good mechanical properties of the resultant joints, low distortion and improved dimensional stability are some of its advantages $[2,4,5]$.

The most important benefits of FSW are its ability to weld materials that were thought difficult to weld such as

\footnotetext{
a Corresponding author:

faramarz_ashenai_ghasemi@yahoo.com
}

plastics and composites [6]. There have been a number of research works to study the effects of FSW process parameters such as tool rotational speed, linear speed, axial force and tilt angle on material flow, microstructure formation and mechanical properties of friction stir welded joints of metals and composites [7-13]. PP composites have already been joined by some of the welding or bonding techniques $[6,14,15]$, but there is still a serious lack of published report regarding FSW of these composites. It is therefore believed that FSW of PP composites deserves more investigation. Schematic view of friction stir welding process is shown in Figure 1 [16].

Polymeric materials offer benefits in comparison to metals and ceramics. Polymers have relatively good physical and mechanical properties, low density, resistance to chemical materials and reasonable prices, but their strength and temperature range are low $[17,18]$. To increase their strength a reinforcing material in the form of polymer, metal or ceramic components is usually added to them. Composites are materials that are composed of combinations of two or more different materials which will have better properties and wider applications $[19,20]$. Important advantages for the composites that can be named are: high mechanical strength to weight ratio, corrosion resistance, excellent fatigue properties than metals, good 


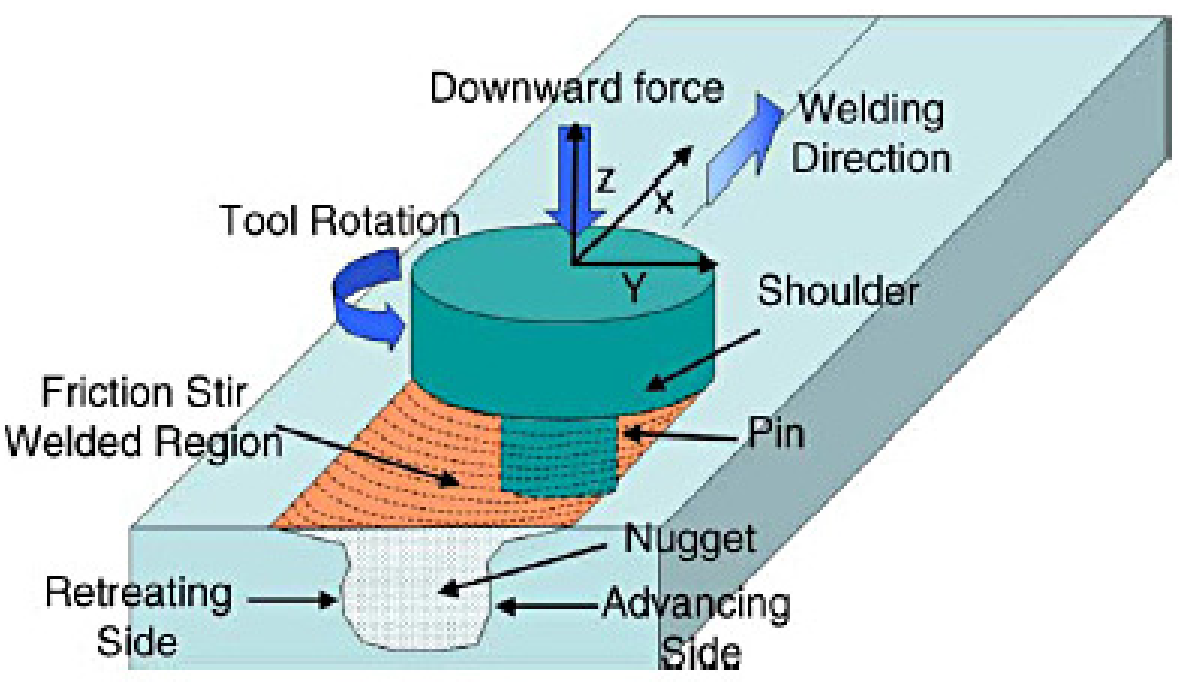

Fig. 1. Schematic of friction stir welding process [16].

thermal insulation properties and rigidity against certain forces [21]. Some composites including fiber reinforced polymer composite (FRPC), especially glass fiber and carbon fiber composites can be used in the body of the aircrafts, ships and automobiles [22].

Researches done by Yosefpour et al. [6] indicate that FSW is a suitable method for welding thermoplastic composites. Scialpi et al. [23] used titanium tool for FSW of PP extruded sheets and compared it with that of common welding methods such as hot gas welding and extrusion. They concluded that mechanical properties of the welds and the welding speed of FSW are higher than the other two methods. Buffa et al. [24] reported that in FSW process, a defect free weld will result only through creating appropriate heat and friction.

Zoltan Kiss et al. [25] used FSW for PP sheets and investigated the effect of parameters such as rotational speed, linear speed and tool geometry on the bond strength. They concluded that the tool geometry had a stronger effect than the other two parameters on bond strength. Saeedi et al. [26] investigated the effect of pin geometry on mechanical properties of polypropylene (PP) composite welded by FSW process. Four different stir pins including of column pin with groove, taper pin with groove, triangle pin and triangle pin with screw thread along with PP matrix 30\% GF composite sheets were studied. The results indicated that pin geometry had a significant effect on weld surface appearance and tensile strength. Also pin affects the flow of the plastic material strongly. The best quality weld and surface appearance and maximum strength were obtained using taper with groove pin in compared to the other tools. The tensile strength of the weld joint reached up to 9 which were $25 \%$ of the base PP composite. They also studied the effect of FSW process parameters on the mechanical properties of PP composites and investigated the effect of parameters such as tool rotational speed, linear speed, tilt angle on tensile strength and hardness of PP composite welds with $30 \%$ glass fiber [13]. It was observed that the specimen welded at the rotational speed of $630 \mathrm{rpm}$ and tilt angle of $2^{\circ}$ showed the maximum tensile strength and hardness whereas linear speeds of 8 and $16 \mathrm{~mm} \cdot \mathrm{min}^{-1}$ caused maximum tensile strength and hardness respectively.

Arab et al. [27] investigated the effects of FSW process parameters (tool pin geometry, tool rotational speed, work linear speed and tool tilt angle) on weld appearance and tensile strength of butt joints in PP composites with $30 \% \mathrm{GF}$ and concluded that the tool pin geometry had a significant influence on weld appearance and the effects of rotational speed and tilt angle on weld appearance and tensile strength were more than that of work linear speed. Increasing the tool rotational speed had an increasing and then a decreasing effect on weld tensile strength. The tool rotational speed of $630 \mathrm{rev} \cdot \mathrm{min}^{-1}$. produced the strongest weld. Increasing the work linear speed from 8 to $20 \mathrm{~mm} \cdot \mathrm{min}^{-1}$. had a decreasing effect on tensile strength. Tensile strength of the welds increased when tilt angle was changed from 0 to $2^{\circ}$.

De Filippis et al. [28] studied the effects of different shoulder geometries on the mechanical and microstructural properties of friction stir welded $6082 \mathrm{~T} 2$ aluminum alloy in the thickness of $1.5 \mathrm{~mm}$. The three studied tools differed from shoulders with scroll and fillet, cavity and fillet, and only fillet. The results showed that, for thin sheets, the best joint has been produced by a shoulder with cavity and fillet.

Ahmadi et al. [29] investigated the effect of tool pin profile on surface appearance and tensile shear strength of friction stir lap welds in carbon fiber reinforced polypropylene composites with $4 \mathrm{~mm}$ thickness. Four high speed steel tools with different pin profiles of threaded cylindrical, threaded cylindrical-conical, simple cylindrical-conical and threaded conical were employed. Using these tools, lap welds were made under similar conditions of tool rotational speed, welding speed and tilt angle. Specimens were prepared for tensile shear testing. The tensile shear test results showed that the threaded cylindrical-conical tool produced a weld without any 
surface porosity and voids so better surface appearance and higher tensile shear strength in comparison to other tools. They also [30] studied the effects of important friction stir welding process parameters such as tool rotational speed, welding speed, tilt angle and tool pin geometry on tensile shear strength of lap joining polypropylene composite plates having $20 \mathrm{wt} \%$ glass fiber using the Minitab software and the Taguchi method of design of experiments. The results indicated that the tensile shear strength was maximum when rotational speed, welding speed, tilt angle and tool pin geometry were 1000 rev. $\mathrm{min}^{-1}$, $20 \mathrm{~mm} \cdot \mathrm{min}^{-1}$ and $1^{\circ}$ respectively with threaded cylindrical-conical tool. Analysis of variance was performed to calculate the percentage of contribution of each factor on tensile shear strength. It was found that, the rotational speed, welding speed, tool pin geometry and tilt angle were significant factors respectively.

Bilici [31] studied the effects of friction stir spot welding parameters (dwell time, tool plunge depth and tool rotational speed) on PP sheet weld strength with the help of the Taguchi method. It was found that, all the parameter were effective on joint strength of PP friction stir spot welds with the dwell time being the dominant parameter and the tool rotational speed the least important one.

Iuri Boromei et al. [32] studied the effect of the Friction Stir Welding process on the microstructure and impact toughness of the two compositesW6A20A (AA6061 reinforced with 20vol. $\%$ of $\mathrm{Al}_{2} \mathrm{O}_{3}$ particles) and W7A10A (AA7005 reinforced with $10 \mathrm{vol} . \%$ of $\mathrm{Al}_{2} \mathrm{O}_{3}$ particles). The results showed that FSW, because of the concurrent effect of severe plastic deformation and frictional heating during welding, had effects both on the reinforcing particles and the aluminum matrix. It induced a significant reduction in the reinforcement particles size and their better distribution in the welded zone as well as a grain refinement of the aluminum alloy matrix in the nugget due to dynamic recrystallization. The frictional heating, moreover, had effects on the growth, dissolution and re-precipitation of hardening precipitates. The impact tests showed that the total impact energies increased in the FSW composites, respect to the corresponding base materials.

In this study, the influence of different parameters such as tool rotational speed linear speed and tilt angle on mechanical properties such as tensile strength and Izod impact of two types of polypropylene composite plates with $30 \%$ glass and $30 \%$ carbon fiber with $5 \mathrm{~mm}$ thickness have been investigated. The best tool pin geometry used in this study was obtained using the threaded taper pin with chamfer according to the previous research [33].

\section{Experimental procedures}

\subsection{Material}

To reach to above purpose, two different types of PP composite plates with $30 \%$ random chopped short glass fiber (GF) and chopped short carbon fiber (CF) and $100 \mathrm{~mm} \times 50 \mathrm{~mm} \times 5 \mathrm{~mm}$ size were used as the parent material. The length of the glass and carbon fiber

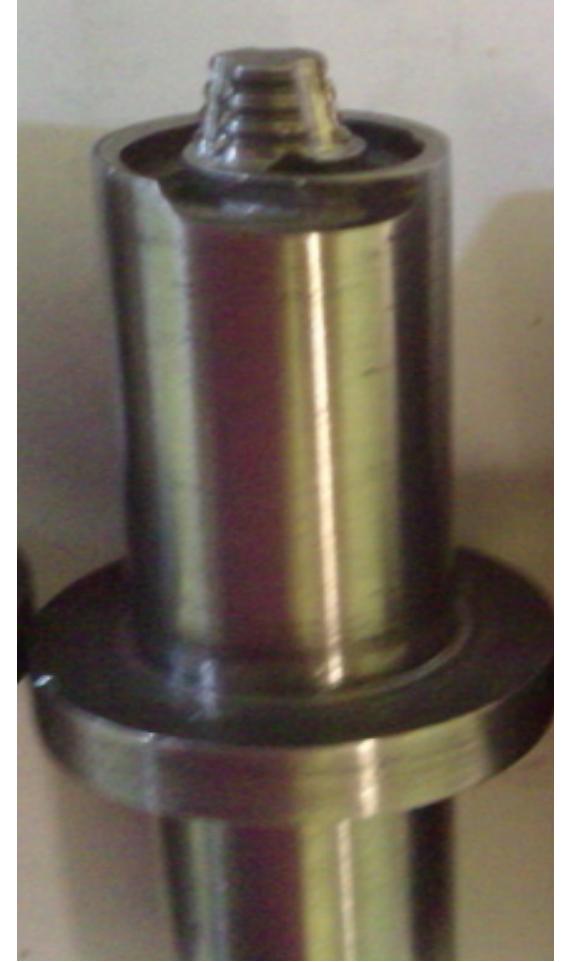

Fig. 2. Worm shoulder tool with threaded tapered and chamfered pin [33].

was about $0.2-0.3 \mathrm{~mm}$. Characteristics of the samples and tools are given in Tables 1 and 2, respectively.

The tools material was a heat treated steel having a threaded taper pin with chamfer as shown in Figure 2. The pin of the tool had a diameter of $5 \mathrm{~mm}$ and was $4.8 \mathrm{~mm}$ long. A $15 \mathrm{~mm}$ diameter shoulder was used. The decision on tool geometry selection was taken on the basis of a previous work [33].

\subsection{Welding procedure}

After fixing the plates in position by using mechanical clamps butt joint welding along the length of the plates was done. Single pass welding procedure was employed to make the joints using the values of the process parameters given in Table 3 . Welding was carried out by using the one factor at a time method.

Design of experiments was done using the Taguchi design method because it is a simple and robust technique for optimizing the welding parameters [34]. The L16 matrix with this method is shown in Table 4.

\subsection{Measurement of tensile strength and Izod impact}

After welding specimens according to ASTM D3039 [35] were prepared for tensile tests to determine their ultimate tensile strength as shown in Figure 3. The tensile tests were carried out Zuker tensile machine. Impact test of the welds was done using Resil impactor 
Table 1. Characteristics of the samples.

\begin{tabular}{cccccc}
\hline $\begin{array}{c}\text { Matrix } \\
(\text { Base })\end{array}$ & $\begin{array}{c}\text { Fiber } \\
\text { type }\end{array}$ & $\begin{array}{c}\text { Percent of } \\
\text { fiber }(\%)\end{array}$ & $\begin{array}{c}\text { Ultimate strength } \\
(\mathrm{MPa})\end{array}$ & $\begin{array}{c}\text { Elongation } \\
(\%)\end{array}$ & $\begin{array}{c}\text { Impact strength } \\
\left(\mathrm{kJ}^{-\mathrm{mm}^{-2}}\right)\end{array}$ \\
\hline $\mathrm{PP}$ & Short glass fiber & 30 & 31 & 3.2 & 10.65 \\
$\mathrm{PP}$ & Short carbon fiber & 30 & 28 & 5.6 & 6.91 \\
\hline
\end{tabular}

Table 2. Chemical composition (\% wt.) of the tools.

\begin{tabular}{cccccccccc}
\hline $\mathrm{Fe}$ & $\mathrm{C}$ & $\mathrm{Si}$ & $\mathrm{Mn}$ & $\mathrm{P}$ & $\mathrm{Cr}$ & $\mathrm{Ni}$ & $\mathrm{Cu}$ & $\mathrm{V}$ & $\mathrm{S}$ \\
\hline Base & 1.72 & 0.59 & 0.36 & 0.024 & 9.98 & 0.07 & 0.036 & 0.049 & 0.027 \\
\hline
\end{tabular}

Table 3. Range of friction stir welding parameters for both GF and CF composites.

\begin{tabular}{cccc}
\hline $\begin{array}{c}\text { Rotational speed } \\
(\mathrm{rpm})\end{array}$ & $\begin{array}{c}\text { Linear speed } \\
\left(\mathrm{mm} . \mathrm{min}^{-1}\right)\end{array}$ & $\begin{array}{c}\text { Tilt angle } \\
(\text { degree })\end{array}$ & $\begin{array}{c}\text { Type of fiber } \\
(\mathrm{G} \text { or C) }\end{array}$ \\
\hline 1250 & 8 & 3 & Glass \\
1600 & 12 & 4 & Carbon \\
2000 & 16 & 5 & \\
2500 & 20 & 6 & \\
\hline
\end{tabular}

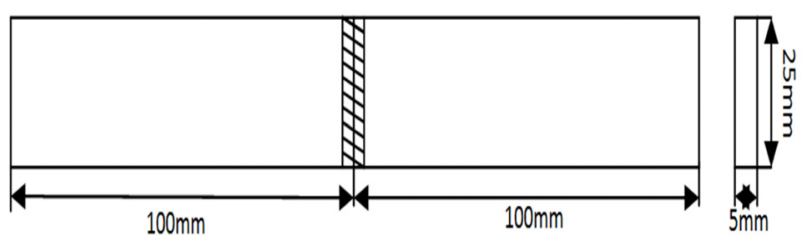

Fig. 3. Standard tensile test specimen geometry and dimensions $(\mathrm{mm})$.

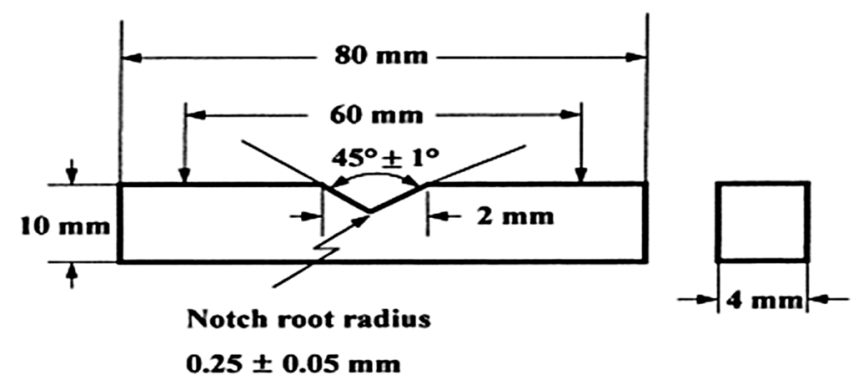

Fig. 4. Geometry of the Izod V-notch impact specimen (mm).

machine according to ISO 180 [36]. Figure 4 shows the geometry of the Izod impact specimen used in this investigation.

\section{Results and discussion}

Figures 5-8 show the effect of FSW process parameters on tensile strength of the joints. Figure 9 shows the effect of FSW process parameters on impact strength of the joints. Table 5 also shows the value of friction stir welding parameters and tensile and impact strength. Attending to Figures 5-9 and Table 5, the following results are obtained.

\subsection{Tensile strength results}

Figure 5A shows the influence of tool rotational speed on tensile strength of the joints. In this case, linear speed and tilt angle were kept constant. When rotational speed increased; the tensile strength increased and then decreased. The tensile strength reached the maximum value of about $10.7 \mathrm{MPa}$ at the tool rotational speed of 2000 rev. $\mathrm{min}^{-1}$ (Table 5). When the rotational speed was less than 2000 rev. $\mathrm{min}^{-1}$, wormhole at the retreating side of the weld was observed which could be due to insufficient heat generation and insufficient matrix transportation [37]. Wormhole is a type of defect which usually occurs in FSW when the ratio between the welding speed and the tool rotational speed are too high or too low. This defect is shown in the weld zone of one sample by some arrows (Fig. 6) [38]. Tunnel defect may occur at high or low tool advance per revolution. Defect location depend is dependent on the material being welded and the welding locations. However, this defect is not normally visible on the surface. It is observed that tunneling and all other defects in FSW occur due to improper selection of welding process parameters (Fig. 7) [39]. As shown in Figure 5A, when the rotational speed was more than $2000 \mathrm{rev} \cdot \mathrm{min}^{-1}$, tunnel defect was observed which may be attributed to excessive turbulence caused by higher rotational speed. Therefore at the rotational speed of $2000 \mathrm{rev} \cdot \mathrm{min}^{-1}$ specimens had the highest tensile strength.

Figure 5B illustrates the effect of linear speed on tensile strength of the welds. Here, rotational speed and tilt angle were kept constant. When linear speed increased, the tensile strength started decreasing. Maximum tensile strength of about 10.7 $\mathrm{MPa}$ was obtained at the linear speed of $8 \mathrm{~mm} \cdot \mathrm{min}^{-1}$. When the linear speed was increased from 8 to $20 \mathrm{~mm} . \mathrm{min}^{-1}$, void defects were observed due to excessive heat input per unit length of the weld and no vertical movement of the material (see Fig. 8). When the welding speed was increased, tunnel defect at the bottom of the weld in the retreating side 
F. Kordestani et al.: Mechanics \& Industry 17, 611 (2016)

Table 4. Range of friction stir welding parameters according to DOE.

\begin{tabular}{ccccc}
\hline $\begin{array}{c}\text { Number of } \\
\text { experiments }\end{array}$ & $\begin{array}{c}\text { Rotational speed } \\
(\mathrm{rpm})\end{array}$ & $\begin{array}{c}\text { Linear speed } \\
\left(\mathrm{mm} . \mathrm{min}^{-1}\right)\end{array}$ & $\begin{array}{c}\text { Tilt angle } \\
(\text { degree })\end{array}$ & $\begin{array}{c}\text { Type of fiber } \\
(\mathrm{G} \text { or C) }\end{array}$ \\
\hline 1 & 1250 & 8 & 3 & Glass \\
2 & 1250 & 12 & 4 & Glass \\
3 & 1250 & 16 & 5 & Carbon \\
4 & 1250 & 20 & 6 & Carbon \\
5 & 1600 & 8 & 4 & Carbon \\
6 & 1600 & 12 & 3 & Carbon \\
7 & 1600 & 16 & 6 & Glass \\
8 & 1600 & 20 & 5 & Glass \\
9 & 2000 & 8 & 5 & Glass \\
10 & 2000 & 12 & 6 & Glass \\
11 & 2000 & 16 & 3 & Carbon \\
12 & 2000 & 20 & 4 & Carbon \\
13 & 2500 & 8 & 6 & Carbon \\
14 & 2500 & 12 & 5 & Carbon \\
15 & 2500 & 16 & 4 & Glass \\
16 & 2500 & 20 & 3 & Glass \\
\hline
\end{tabular}

\section{Main Effects Plot (data means) for Means}

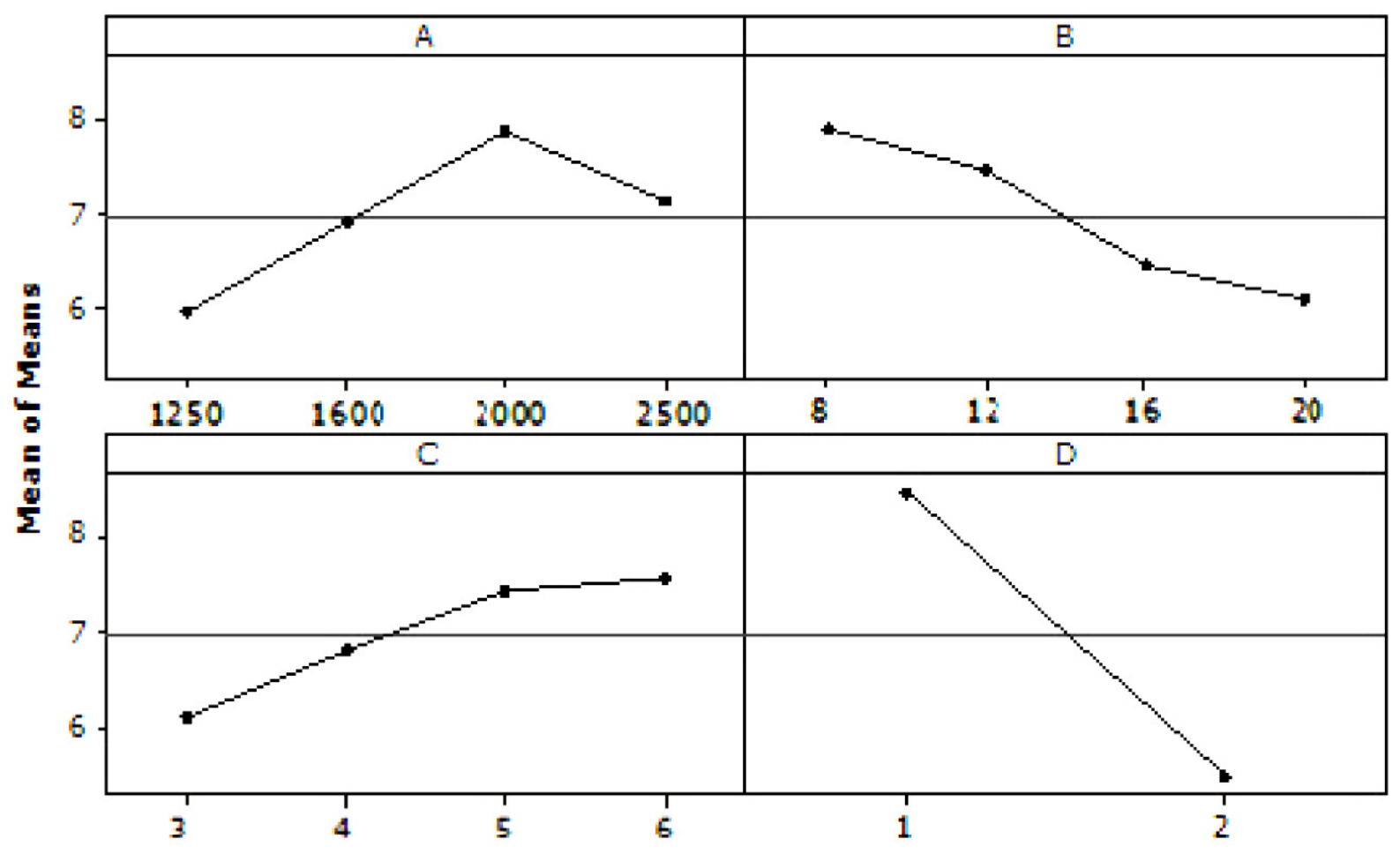

Fig. 5. (A) Effect of rotational speed (B) linear speed, (C) tilt angle and (D) fiber type on tensile strength.

was observed due to insufficient heat input caused by inadequate flow of matrix. Hence by increasing the linear speed; the tensile strength decreased slightly. Therefore as shown in Figure 5B, the linear speed does not have much effect on the tensile strength of the welds.

The effect of tilt angle on tensile strength of the welds is given in Figure 5C. Here, rotational and linear speeds were kept constant. By increasing the tilt angle, the tensile strength started to increase. The specimen welded at $6^{\circ}$ of tilt angle showed the highest tensile strength of about $10.7 \mathrm{MPa}$. When the tilt angle was $3^{\circ}$, tunnel and crack like defects at the middle of the weld cross section in the retreating side were observed because of insufficient vertical and horizontal flow of the material. At the tilt angle of $6^{\circ}$, movement of the tool forges the material into the weld zone and causes the holes and porosities to be filled. Therefore when the tilt angle is increased from $3^{\circ}$ to $6^{\circ}$; the tensile strength increases but at different rates.

Figure 5D shows the effect of type of fiber on tensile strength of the welds. As shown in Figure 5D, the tensile 


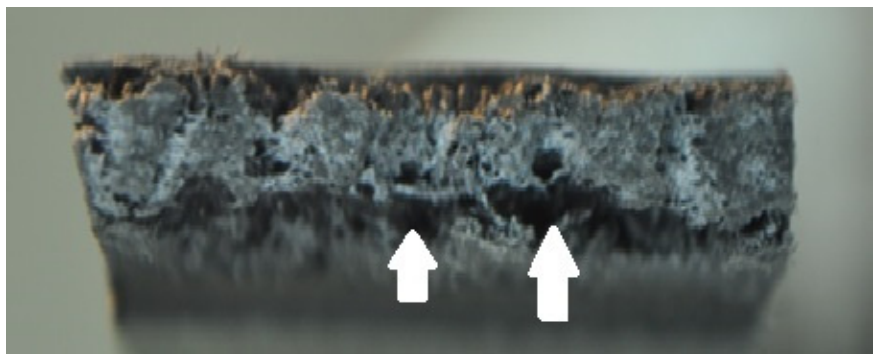

Fig. 6. Wormhole defect.

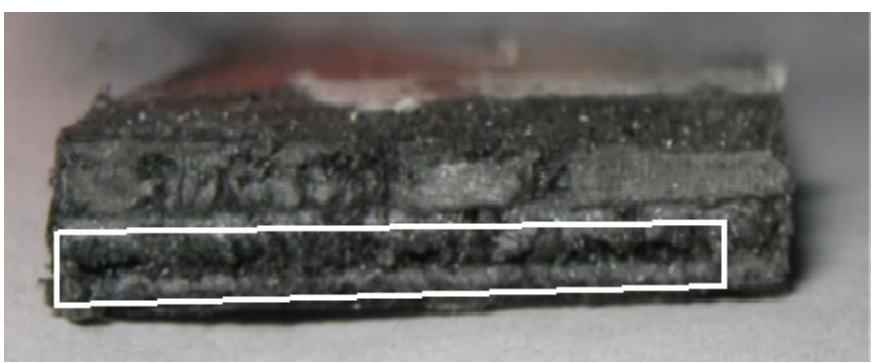

Fig. 7. Tunnel defect in stir zone.

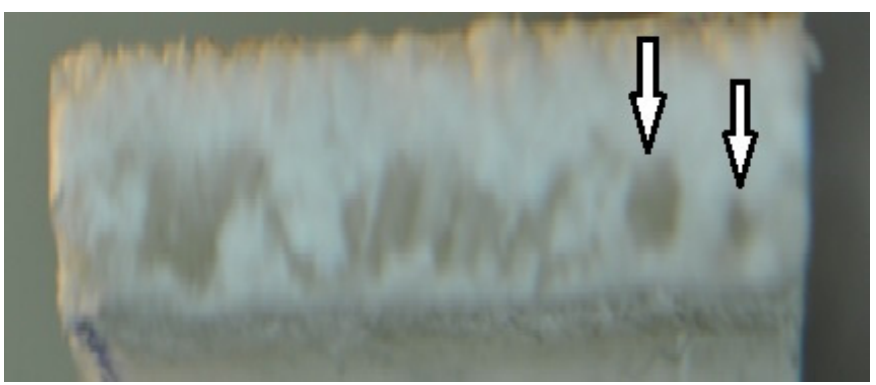

Fig. 8. Voids defect.

strength of the weld is higher when glass fiber (code 1 in horizontal axis) is used as the reinforcing material compared to when carbon fiber (code 2 in horizontal axis) is used.

\subsection{Impact strength test results}

Figure 9 shows the effect of FSW process parameters on impact strength of the joints. Figure 9A shows the influence of tool rotational speed on impact strength of the joints. Here, linear speed and tilt angle were kept constant. When rotational speed increased; the impact strength increased. The impact strength reached the maximum value of about $4.12 \mathrm{~kJ} . \mathrm{mm}^{-2}$ at the tool rotational speed of 2500 rev. $\mathrm{min}^{-1}$. When the rotational speed was less than 2500 rev. $\mathrm{min}^{-1}$, wormhole at the retreating side of the weld was observed which could be due to insufficient heat generation and insufficient matrix transportation.

The linear speed influence on impact strength of the welds is shown in Figure 9B. Here, rotational speed and tilt angle were kept constant. Similar to the specimens tested for tensile strength, in this case also; increasing the linear speed decreased the impact strength. Maximum impact strength was obtained at the linear speed of $8 \mathrm{~mm} \cdot \mathrm{min}^{-1}$. When linear speed increases from 8 to $20 \mathrm{~mm} \cdot \mathrm{min}^{-1}$, because of loss of fiber on the surface of weld and formation of tunnel defect at the bottom of the weld in the retreating side due to insufficient heat input caused by inadequate flow of matrix impact strength decreased.

Figure 9C shows the effect of tilt angle on impact strength of the welds. Here, rotational speed and speeds were kept constant. When tilt angle increased, the impact strength increased and then decreased. The specimens welded at $5^{\circ}$ of tilt angle showed the highest impact strength of about $4.12 \mathrm{~kJ} . \mathrm{mm}^{-2}$.

Figure 9D shows the effect of type of fiber on impact strength of the welds. As shown in the figure glass fiber has more influence on impact strength due to its more mechanical properties and better distortion in the field.

As seen from Figures 5B, 9B and 5D, 9D; the effects of tool tilt angle and type of fiber on tensile strength and impact strength of the welds are almost the same.

\section{Conclusions}

In this paper, $\mathrm{PP}$ based composite plates with $30 \%$ short glass fiber and $30 \%$ short carbon fiber were welded using FSW process. The effects of tool rotational speed, linear speed tilt angle and type of fiber on tensile strength and Izod impact of the welds were investigated experimentally. Due to reducing number of experiments and prices, Taguchi method was done. The results indicated that:

- Among the design of experiment parameters, type of fiber has the most effect on tensile strength and then linear speed, rotational speed and tilt angle are the significant parameters on tensile strength respectively.

- Also among the design of experiment parameters, type of fiber has the most effect on impact strength and then rotational speed tilt angle and linear speed are the significant parameters on impact strength respectively.

- For GF composites the specimen welded at the rotational speed of $2000 \mathrm{rpm}$, linear speed of $8 \mathrm{~mm} . \mathrm{min}^{-1}$ and tilt angle of $6^{\circ}$ showed the maximum tensile strength.

- For CF composites the specimen welded at the rotational speed of $2500 \mathrm{rpm}$, linear speed of $8 \mathrm{~mm} \cdot \mathrm{min}^{-1}$ and tilt angle of $6^{\circ}$ showed the maximum tensile strength.

- Also the maximum impact strength occurred at the rotational speed of $2500 \mathrm{rpm}$, linear speed of $8 \mathrm{~mm} \cdot \mathrm{min}^{-1}$ whereas tilt angle of 5 and $6^{\circ}$, caused maximum impact strength for $\mathrm{GF}$ and $\mathrm{CF}$ composites respectively. 
F. Kordestani et al.: Mechanics \& Industry 17, 611 (2016)

Table 5. The value of friction stir welding parameters, tensile and impact strength.

\begin{tabular}{ccccccc}
\hline $\begin{array}{c}\text { Number of } \\
\text { experiments }\end{array}$ & $\begin{array}{c}\text { Rotational speed } \\
(\mathrm{rpm})\end{array}$ & $\begin{array}{c}\text { Linear speed } \\
\left(\mathrm{mm} . \mathrm{min}^{-1}\right)\end{array}$ & $\begin{array}{c}\text { Tilt angle } \\
(\text { Degree })\end{array}$ & $\begin{array}{c}\text { Type of } \\
\text { fiber }\end{array}$ & $\begin{array}{c}\text { Tensile strength } \\
(\mathrm{MPa})\end{array}$ & $\begin{array}{c}\text { Impact strength } \\
\left(\mathrm{kJ} . \mathrm{mm}^{-2}\right)\end{array}$ \\
\hline 1 & 1250 & 8 & 3 & Glass & 7.4 & 2.84 \\
2 & 1250 & 12 & 4 & Glass & 7.8 & 2.99 \\
3 & 1250 & 16 & 5 & Carbon & 4.5 & 2.54 \\
4 & 1250 & 20 & 6 & Carbon & 4.2 & 2.34 \\
5 & 1600 & 8 & 4 & Carbon & 6.3 & 2.79 \\
6 & 1600 & 12 & 3 & Carbon & 5.0 & 3.31 \\
7 & 1600 & 16 & 5 & Glass & 8.4 & 3.11 \\
8 & 1600 & 20 & 5 & Glass & 8.0 & 3.12 \\
9 & 2000 & 8 & 6 & Glass & 10.7 & 2.61 \\
10 & 2000 & 12 & 6 & Glass & 10.5 & 2.55 \\
11 & 2000 & 16 & 3 & Carbon & 5.0 & 3.53 \\
12 & 2000 & 20 & 4 & Carbon & 5.2 & 3.29 \\
13 & 2500 & 8 & 6 & Carbon & 7.1 & 3.59 \\
14 & 2500 & 12 & 5 & Carbon & 6.5 & 3.13 \\
\hline
\end{tabular}

Main Effects Plot (data means) for Means

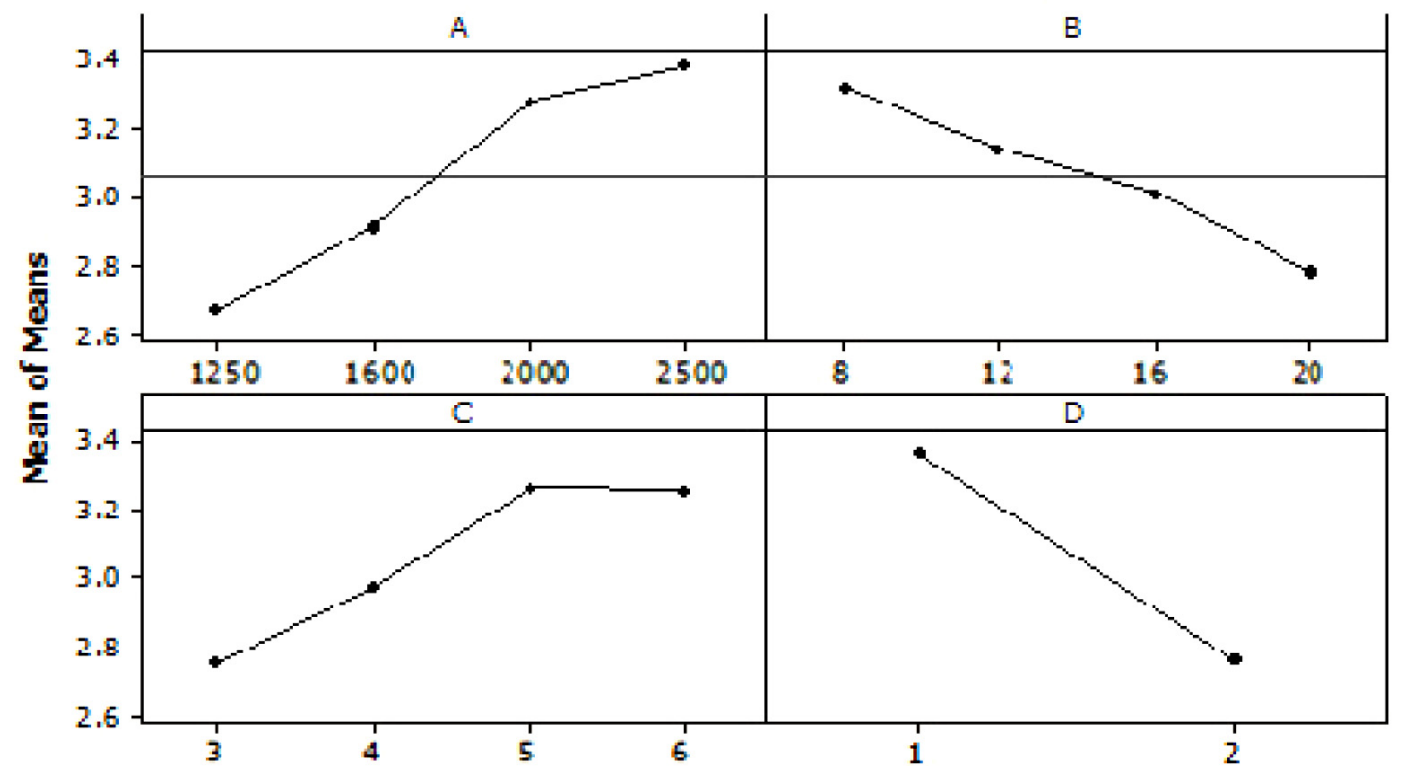

Fig. 9. (A) Effect of rotational speed, (B) linear speed, (C) tilt angle and (D) fiber type on impact strength.

\section{References}

[1] R. Palanivel, P. Koshy Mathews, N. Murugan, Influences of Tool Pin Profile on the Mechanical and Metallurgical Properties of Friction Stir Welding of Dissimilar Aluminum Alloy, Int. J. Eng. Sci. Technol. 2 (2010) $2109-2115$

[2] M.J. Peel, A. Steuwer, P.J. Withers, T. Dickerson, Q. Shi, H. Shercliff, Dissimilar friction stir welds in aa5083aa6082, Metal. Mater. Trans. 37 (2006) 2183-2193

[3] Yingchun Chen, Huijie Liu, Jicai Feng., Frictions stir welding characteristics of different heat- treated-state 2219 aluminum alloy plates, Mater. Sci. Eng. A 420 (2006) 21-25
[4] A. Barcellona, G. Buffa, L. Fratini, D. Palmeri, On microstructural phenomena occurring in friction stir welding of aluminum alloys, J. Mater. Process. Technol. 177 (2006) 340-343

[5] T.A. Dikerson, J. Przydatek, Int. J. Fatigue 25 (2003) 1399-1409

[6] A. Yousefpour, M. Hojjati, J.P. Immarigeon, Fusion bonding/welding of thermoplastic composites, J. Thermoplast. Compos. Mater. 17 (2004) 303-341

[7] T. Saeid, A. Abdollah-Zadeh, H. Assadi, F. Malek Ghaini, Effect of Friction Stir Welding Speed on the Microstructure and Mechanical Properties of a Duplex Stainless Steel, Mater. Sci. Eng. 496 (2008) 262-268

[8] S.R. Ren, Z.Y. Ma, L.Q. Chen, Effect of Welding Parameters on Tensile Properties and Fracture Behavior of Friction Stir Welded Al-Mg-Si alloy, Scr. Mater. 56 (2007) 69-72 
[9] P. Cavaliere, G. Campanile, F. Panella, A. Squillace, Effect of Welding Parameters on Mechanical and Microstructural Properties of AA6056 Joints Produced by Friction Stir Welding, J. Mater. Process. Technol. 180 (2006) 263-270

[10] P. Cavaliere, A. Squillace, F. Panella, Effect of Welding Parameters on Mechanical and Microstructural Properties of AA6082 Joints Produced by Friction Stir Welding, J. Mater. Process. Technol. 200 (2008) 364-372

[11] M. Abbasi Gharacheh, A.H. Kokabi, G.H. Daneshi, B. Shalchi, R. Sarrafi, The influence of the ratio of rotational speed/traverse speed $(\mathrm{o} / \mathrm{v})$ on mechanical properties of AZ31 friction stir welds, Int. J. Machine Tools Manuf. 46 (2006) 1983-1987

[12] M. Amirizad, A.H. Kokabi, M. Abbasi Gharacheh, R. Sarrafi, B. Shalchi, M. Azizieh, Evaluation of microstructure and mechanical properties in friction stir welded A $356+15 \% \mathrm{SiCp}$ cast composite, Mater. Lett. 60 (2006) $565-568$

[13] M. Saeidi Boroujeni, N.B. Mostafa Arab, F. Ashenai Ghasemi, A Study of FSW Process Parameters Effects on Mechanical Properties of PP Composites 11th Iranian Conference on Manufacturing Engineering, 2010

[14] R. Rudolf, P. Mitschang, M. Neitzel, C. Rueckert, Welding of High-PerformanceThermoplastic Composites, Polym. Polym. Compos. 7 (1999) 309-315

[15] D.M. Maguire, Joining Thermoplastic Composites, SAMPE J. (1989) 25 11-14

[16] R.S. Mishraa, Z.Y. Mab, Friction stir welding and processing Mater. Sci. Eng. 50 (2005) 1-78

[17] H. Becker, C. Gartner, Polymer microfabrication technologies for microfluidic systems, Anal. Bioanal. Chem. 390 (2008) 89-111

[18] J. Dwyer, M. Betts, Polymer-Modified Asphalt: Improving Our Nation's Infrastructure, 11th Annual Freshman Conference, 2011, pp. 1224-33

[19] D. Roylance, Introduction to Composite Materials, Department of Materials Science and Engineering, Massachusetts Institute of Technology, Cambridge, MA 02139, 2000

[20] Hatsuo Ishida, Introduction to Polymer Composite Processing, 2010

[21] N. Ranu, G. Oprian, D. Isopescu, I. Enuc, V. Munteanu, Banu Ctlin Fibre Reinforced Polymer Composites As Internaland External Reinforcements For Building Elements Buletinul Institutului Politehnic, 2008

[22] H. Fukuyama, FRP Composites in Japan, Concrete Int. 21 (1999) 29-32

[23] A. Scialpi, M. Troughton, S.L. Andrews, In-Line Reciprocating Friction Stir welding of Plastics, Joining Plastics Magazine 1 (2007) 1-8

[24] G. Buffa, J. Hua, R. Shivpuri, L. Fratini, Design of the Friction Stir Welding Tool Using the Continuum Based FEM Model, Mater. Sci. Eng. A 419 (2006) 381-388

[25] Z. Kiss, T. Czigány, Applicability of friction stir welding in polymeric materials, Mech. Eng. 51 (2007) 15-18

[26] B.M. Saeidi, M. Arab NB, F.A. Ashenai Ghasemi, G.h. Payeganeh, The Effect of Pin Geometry on Mechanical Properties of PP Composite Friction Stir Welds, IIW International Congress on Welding and Joining, 2009
[27] G.H. Payganeh, N.B. Mostafa Arab, Y. Dadgar Asl, F.A. Ashenai Ghasemi, M. Saeidi Boroujeni, Effects of friction stir welding process parameters on appearance and strength of polypropylene composite welds, Int. J. Phys. Sci. 6 (2011) 4595-4601

[28] A. Scialpi, L.A.C. De Filippis, P. Cavaliere, Influence of shoulder geometry on microstructure and mechanical properties of friction stir welded 6082 aluminium alloy, Mater. Design 28 (2007) 1124-1129

[29] H. Ahmadi, N.B. Mostafa Arab, F. Ashenai Ghasemi, R. Eslami Farsani, Influence of Pin Profile on Quality of Friction Stir Lap Welds in Carbon Fiber Reinforced Polypropylene Composite, Int. J. Mech. Appl. 2 (2012) $1-5$

[30] H. Ahmadi, N.B. Mostafa Arab, F. Ashenai Ghasemi, Application of Taguchi method to optimize friction stir welding parameters for polypropylene composite lap joints, Arch. Sci. 65 (2012) 59-74

[31] M.K. Bilici, Application of Taguchi approach to optimize friction stir spot welding parameters of polypropylene, Mater. Design 35 (2011) 113-119

[32] L. Boromei, L. Ceschini, A. Morri, G.L. Garagnani, Friction stir welding of aluminium based composites reinforced with $\mathrm{Al}_{2} \mathrm{O}_{3}$ Particles: Effects on Microstructure and Charpy Impact Energy, Metall. Sci. Technol. 24 (2008) 12-21

[33] F. Kordestani, N.B. Mostafa Arab, F. Ashenai Ghasemi, R. Eslami Farsani, Experimental Investigation of Pin Geometry Influence on Tensile Strength of Friction Stir Welds in Polypropylene Composites, 3rd international conference on manufacturing engineering ICME2011, Tehran, Iran 2011

[34] S.C. Juang, Y.S. Tarng, Process parameter selection for optimizing the weld pool geometry in the tungsten inert gas welding of stainless steel, J. Mater. Process. Technol. 122 (2002) 33-37

[35] ASTM D 3039 - 76, standard test method for tensile properties of fiber-resin composites, October 1982 25. ISO 180:2000, Plastics determination of Izod impact strength. Geneva: International Organization for Standardization, 2000

[36] ISO 180:2000, Plastics determination of Izod impact strength, Geneva: International Organization for Standardization, 2000

[37] A.K. Lakshminarayanan, V. Balasubramanian, Process parameters optimization for friction stir welding of RDE40 aluminium alloy using Taguchi technique, Trans. Nonferrous Metals Soc. China 18 (2008) 548-554

[38] M. Longo, G. D'Urso, C. Giardini, E. Ceretti, Process Parameters Effect on Mechanical Properties and Fatigue Behavior of Friction Stir Weld AA6060 Joints, J. Eng. Mater. Technol. 134 (2012) 0210061-8

[39] N.Z. Khan, A.N. Siddiquee, Z.A. Khan, S.K. Shihab, Investigations on tunneling and kissing bond defects in FSW joints for dissimilar aluminum alloys, J. Alloys Compd. 648 (2015) 360-367 